Research Article

\title{
Experimental Research on Brittleness and Rockburst Proneness of Three Kinds of Hard Rocks under Uniaxial Compression
}

\author{
Rongchao Xu $\mathbb{D}^{\mathrm{D}}$, Yiding Jin, and Yumin Zhang \\ College of Geosciences and Engineering, North China University of Water Resources and Electric Power, Zhengzhou, \\ Henan 450046, China \\ Correspondence should be addressed to Rongchao Xu; rcxirsm@126.com
}

Received 12 August 2020; Revised 11 September 2020; Accepted 26 June 2021; Published 2 July 2021

Academic Editor: Fengqiang Gong

Copyright ( 2021 Rongchao Xu et al. This is an open access article distributed under the Creative Commons Attribution License, which permits unrestricted use, distribution, and reproduction in any medium, provided the original work is properly cited.

Rockburst is a highly destructive geological disaster caused by excavation and unloading of hard and brittle rock mass under high geostress environment. Quantitative evaluation of rock brittleness and rockburst proneness is one of the important tasks in potential rockburst assessment. In this study, uniaxial compression and acoustic emission tests were carried out for basalt, granite, and marble, and their brittleness and rockburst proneness were quantitatively evaluated. The acoustic emission evolution characteristics of the three rocks during uniaxial compression were analyzed, and the differences of fracture mechanism of the three rocks were compared. The results show that (1) based on the brittleness evaluation index, basalt is the most brittle rock, followed by granite, and marble is the weakest; (2) based on the rockburst proneness evaluation index, combined with the macroscopic failure phenomenon and morphology of the samples, the rockburst proneness of basalt is the strongest, followed by granite, and marble is the weakest; (3) there exists a positive correlation between rockburst proneness and brittleness, and the fitting results show that they are approximately exponential; and (4) brittleness has an important influence on the rock fracture mechanism. Unlike marble, basalt and granite with strong brittleness continuously present high-energy acoustic emission signals in the stage of unstable crack propagation, and large-scale fracture events continue to occur; from the calculation results of the acoustic emission $b$ value, the stronger the brittleness of rock, the larger the proportion of large-scale fracture events in the failure process.

\section{Introduction}

As the representative of dynamic disasters under high stress conditions [1-6], rockburst makes rock mechanics researchers gradually realize the importance of revealing the brittle failure mechanism of rock for engineering safety. Brittleness of rock refers to its ability to resist plastic deformation [7-9], which is a comprehensive reflection of rock mineral composition, grain cementation strength, and structural characteristics. The process of brittle failure of rock includes the initiation, propagation, and coalescence of cracks until the formation of the macroscopic fracture surface. In the aspect of quantitative evaluation of rock brittleness, many scholars put forward a lot of evaluation indexes based on the stress-strain curve of rock. Altindag [10] proposed two brittleness indices according to the peak strength, residual strength, and corresponding peak strain and residual strain in the stress-strain curve. Li et al. [11] summarized twenty basic brittleness evaluation methods and established a comprehensive brittleness evaluation index based on the stress-strain curve. Tarokh et al. [12] treated brittleness as a structural response rather than a material property and proposed two brittleness indices. Ai et al. [13] defined brittleness as the ability of a rock to accumulate elastic energy during the prepeak stage and to self-sustain fracture propagation in the postpeak stage and proposed. Xia et al. [14] proposed a brittleness index based on the postpeak stress drop rate of the stress-strain curve and the ratio of elastic energy released during instability failure to total energy stored before peak strength. Chen et al. [15] comprehensively considered the postpeak stress-drop rate and the stress growth rate between the crack initiation stress and 
the peak stress and established a brittleness index calculation method based on the whole stress-strain curve.

As a nondestructive testing method, acoustic emission technology plays an important role in the rock mechanics test, especially in the crack propagation mechanism. The acoustic emission characteristics are different due to the reason that rocks possess different deformation and failure mechanisms. The commonly used acoustic emission (AE) parameters in the fracture mechanism include $\mathrm{AE}$ count, $\mathrm{AE}$ energy, and AE $b$ value. Eberhardt et al. $[16,17]$ studied the characteristics of fracture initiation strength and damage strength of Lac Du bonnet granite under uniaxial compression by using the acoustic emission test method. It was found that the parameter of the AE count has the advantage of quantitatively describing the stress threshold of rock. The asperity degradation characteristics of soft rock-like fractures under shearing were investigated based on AE energy [18]. Zhou et al. [19] systematically discussed the advantages and disadvantages of $\mathrm{AE}$ parameters in determining the stress threshold value of rock. AE characteristics of Beishan granite under conventional triaxial compression (CTC) and hydromechanical (HM) coupling tests are conducted by Zhou et al. [20], and the results show that AE events proportion at the same loading period changes under different confining pressures, which illustrates that the failure pattern develops from splitting to ductile shearing failure with the increasing confining pressure. Wong and Guo [21] interpreted the microcracking behavior of two specimen types in the mode I fracture toughness test by analyzing acoustic emission catalogs including the spatial-temporal evolution of $\mathrm{AE}$ events, variations of energy-related AE parameters, and the AE event energy distributions.

The rockburst proneness and in-situ stress level are the main factors influencing the rockburst prediction of underground engineering [22-24]. Among them, the evaluation of rockburst proneness is an important basis for the analysis and prediction of rockburst disaster after excavation. There are more than ten kinds of evaluation indexes for rockburst proneness. At present, the widely used rockburst proneness indexes in civil engineering include the peak strength strain energy storage index $W_{\text {et }}^{p}[1]$, maximum stored elastic strain energy index $E_{s}$ [25], elastic energy index $W_{\text {et }}[26,27]$, impact energy index $W_{\text {cf }}[28]$, and residual energy index $W_{R}$ [29].

Brittleness and rockburst proneness are important properties to describe the mechanical characteristics of hard rock. The existing research studies mainly focus on the quantitative evaluation of brittleness and rockburst proneness of rocks with different methods, and there is no systematic research on the relationship between rock brittleness and rockburst proneness; furthermore, the influence law of brittleness on acoustic emission characteristics and the failure mechanism of rock have not been fully investigated. In this study, three types of hard rock basalt, granite, and marble were used to carry out the uniaxial compression test and simultaneous acoustic emission test; combined with the test results and sample failure phenomenon, the brittleness and rockburst proneness of the three kinds of rocks were evaluated; based on the acoustic emission test results, the influence of brittleness on acoustic emission parameters (AE energy, AE count, and AE $b$ value) and failure mechanism of rocks were analyzed. The research results have a certain guiding significance for understanding the brittle failure process and mechanism of hard rock.

\section{Testing System and Specimen}

The instrument used in the uniaxial compression test is the RMT-150C testing machine. In order to obtain the complete stress-strain curve of rock, the axial displacement control method is used to load the sample, and the loading rate is set to $0.12 \mathrm{~mm} / \mathrm{min}$. The acoustic emission system is an 8 channel acoustic emission monitoring system produced by PAC Company. The type of acoustic emission probe is PICO. The acquisition frequency of AE signal is $1 \mathrm{MHz}$. The threshold value of acoustic emission signal is set to $40 \mathrm{~dB}$, which can effectively filter the interference of noise on the acoustic emission signal. The test system is shown in Figure 1.

Rock samples used in the tests were bought from a quarry in Wuhan City, Hubei Province. The basalt, granite, and marble used in the test are standard cylindrical samples with a diameter of $50 \mathrm{~mm} \times$ height of $100 \mathrm{~mm}$. The density of basalt, granite, and marble is $2.97 \mathrm{~g} / \mathrm{cm}^{3}, 2.61 \mathrm{~g} / \mathrm{cm}^{3}$, and $2.85 \mathrm{~g} / \mathrm{cm}^{3}$, respectively. After measurement before the test, the size and accuracy of sample meet the requirements of test specifications according to the IRSM recommended methods.

\section{Analysis of the Test Results}

3.1. Characteristics of Strength. The three diagrams shown in Figure 2 are typical stress-strain curves of three kinds of rocks under uniaxial compression. As listed in Table 1, the stress-strain curves of specimens 1-2, 2-2, and 3-2 are shown in Figure 2 as typical curves. It is not difficult to find that the rock does not show an obvious yield phenomenon before the peak strength, and the axial stress drops rapidly after the peak strength which means that the three kinds of rocks show typical brittle failure characteristics. Compared with marble, the stress-drop rate of basalt and granite after peak strength is faster and the curve is steeper, so the brittle failure of basalt and granite is more obvious.

According to the shape of the stress-strain curve, the uniaxial compression process can be divided into five different stages: crack compaction stage, linear elastic deformation stage, stable crack growth stage, unstable crack propagation, and postpeak failure stage. Among them, the transition from stable crack growth to unstable crack growth means that microcracks in rock begin to connect with each other and form macroscopic fracture surface. The stress value corresponding to the transition point is called the damage strength $\sigma_{c d}$ of rock. Under this stress level, even if the axial compression load does not increase any more, the internal cracks in the rock will continue to expand, eventually leading to the occurrence of rock macrofailure. The stress value is also called the longterm strength of rock [19]. Therefore, the analysis of 


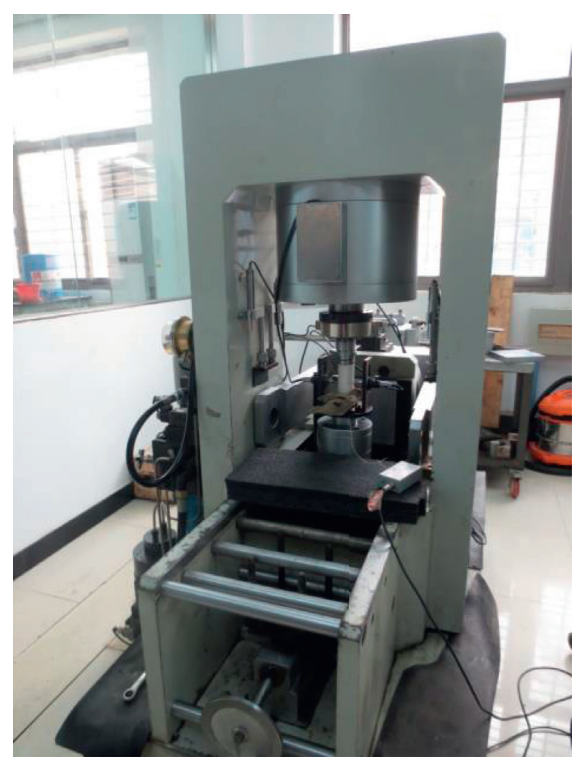

(a)

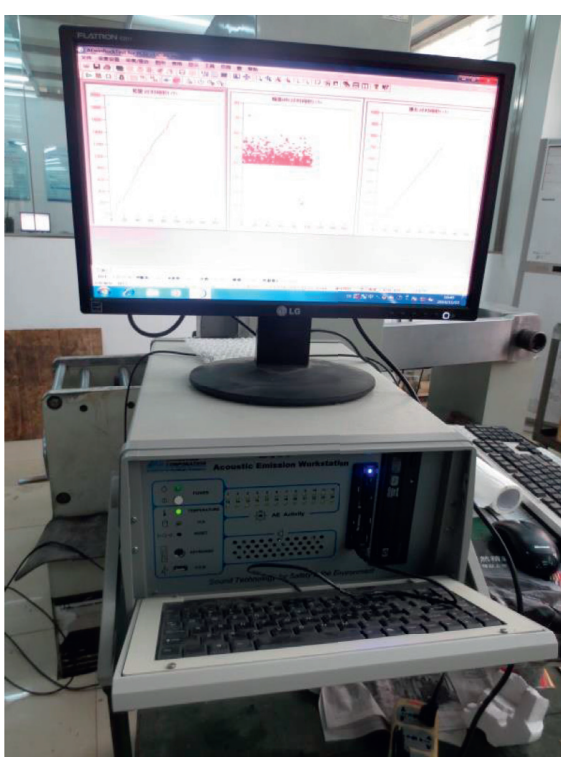

(b)

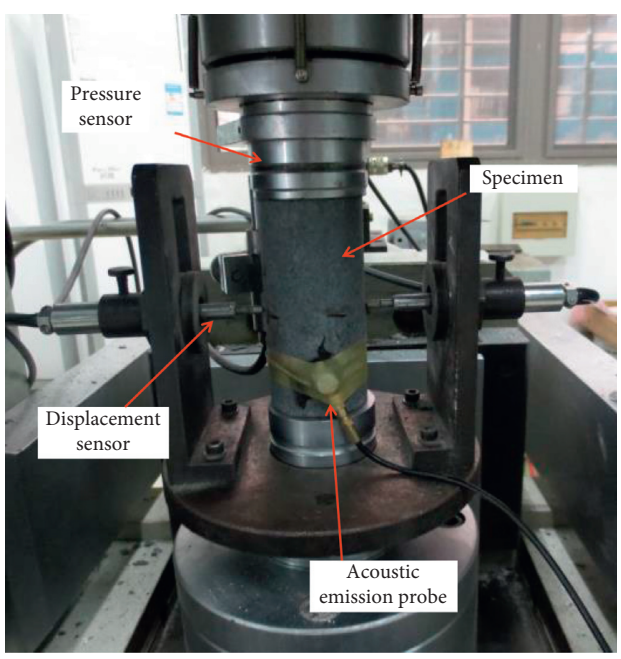

(c)

FIGURE 1: Testing system: (a) loading machine; (b) acoustic emission test system; (c) sensor placement.

damage strength is of great significance to the understanding of brittle failure of rock. The damage strength can be determined according to the volume strain curve or acoustic emission characteristic curve of rock. In this study, the strain measurement method is used to determine the damage strength, that is, the axial stress corresponding to the inflection point of volume strain is the damage strength, as shown in Figure 3. The volume strain is obtained according to the following calculation formula:

$$
\varepsilon_{V}=\varepsilon_{\text {axial }}+2 \varepsilon_{\text {lateral }},
$$

where $\varepsilon_{\text {axial }}$ and $\varepsilon_{\text {lateral }}$ are the axial and lateral strain, respectively.

As given in Table 1, the ratio of damage strength to peak strength $\sigma_{c d} / \sigma_{p}$ of basalt ranges from $70.63 \%$ to $85.90 \%$, with an average of $76.26 \%$, that of granite ranges from $67.60 \%$ to $74.51 \%$, with an average of $70.57 \%$, while that of marble ranges from $43.93 \%$ to $61.46 \%$, with an average of $52.04 \%$. Therefore, the ratio of damage strength to peak strength of basalt is the largest, followed by granite and marble.

3.2. Brittleness Evaluation. Because of the lack of standard definitions and measurement methods for rock brittleness, various brittleness indices have been proposed and used by different authors for their respective practical use [30]. Because of the convenience to conduct compression tests of rocks, indices derived from stress-strain curves are widely used to evaluate rock brittleness. Through summarizing the disadvantages of the indices based on stress-strain curves, Meng et al. [30] proposed a new brittleness index based on the postpeak stress drop degree and drop rate and verified the index through experimental tests. The calculation formula of the index is as follows: 


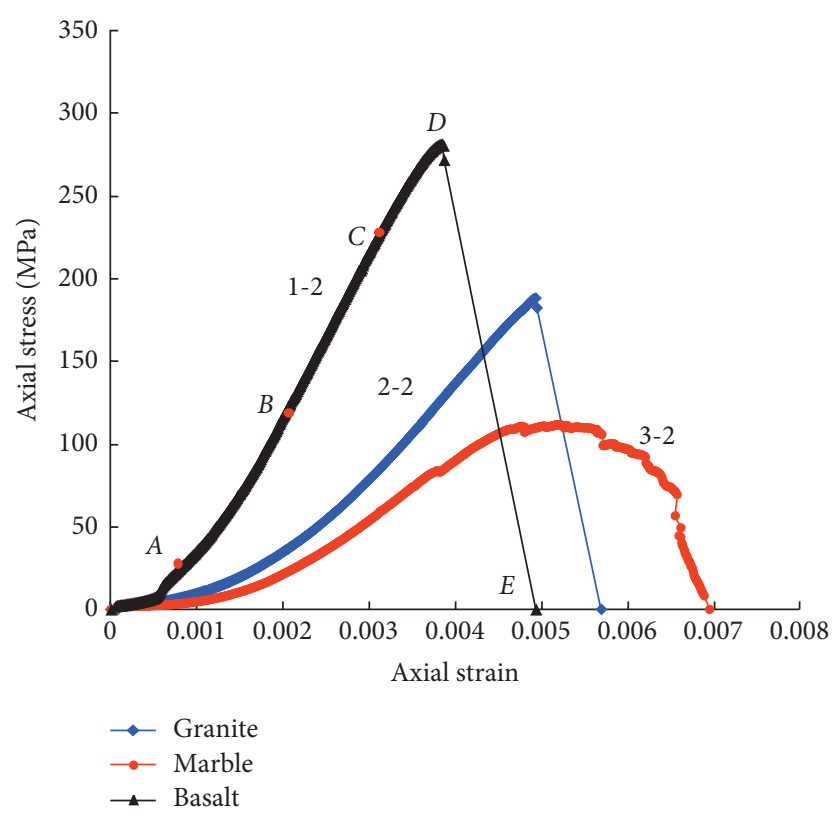

FIgURE 2: Typical stress-strain curves of three kinds of rocks.

TABLE 1: Main mechanical parameters of rock samples.

\begin{tabular}{lccccccccc}
\hline Rock type & Sample no. & $\sigma_{c d}(\mathrm{MPa})$ & $\sigma_{p}(\mathrm{MPa})$ & $\varepsilon_{p}$ & $\sigma_{r}(\mathrm{MPa})$ & $\varepsilon_{r}$ & $E(\mathrm{GPa})$ & $B_{d}$ & $E_{s}\left(\mathrm{MJ} \cdot \mathrm{m}^{-3}\right)$ \\
\hline \multirow{3}{*}{ Basalt } & $1-1$ & 198.76 & 281.43 & 0.00383 & 0 & 0.00493 & 85.79 & 0.541 \\
& $1-2$ & 208.28 & 288.32 & 0.00503 & 0 & 0.00600 & 71.41 & 0.547 & 0.462 \\
& $1-3$ & 228.05 & 265.41 & 0.00561 & 0 & 0.00617 & 73.65 & 0.568 & 0.478 \\
\hline \multirow{3}{*}{ Granite } & $2-1$ & 135.86 & 200.98 & 0.00503 & 0 & 0.00589 & 55.63 & 0.537 & 0.363 \\
& $2-2$ & 131.08 & 188.32 & 0.00493 & 0 & 0.00569 & 55.41 & 0.539 & 0.309 \\
& $2-3$ & 153.93 & 206.58 & 0.00494 & 0 & 0.00865 & 53.28 & 0.475 & 0.400 \\
\multirow{3}{*}{ Marble } & $3-1$ & 55.07 & 125.37 & 0.00364 & 0 & 0.0054 & 54.50 & 0.485 & 0.144 \\
& $3-2$ & 56.74 & 111.83 & 0.00521 & 0 & 0.00695 & 35.82 & 0.481 & 0.175 \\
& $3-3$ & 76.38 & 124.27 & 0.00444 & 0 & 0.00627 & 44.47 & 0.483 & 0.175 \\
\hline
\end{tabular}

$\sigma_{c d}, \sigma_{p}, \sigma_{r}$ are the damage stress, peak strength, and residual strength, respectively; $\varepsilon_{p}$ and $\varepsilon_{r}$ are the peak strain and residual stain, respectively.

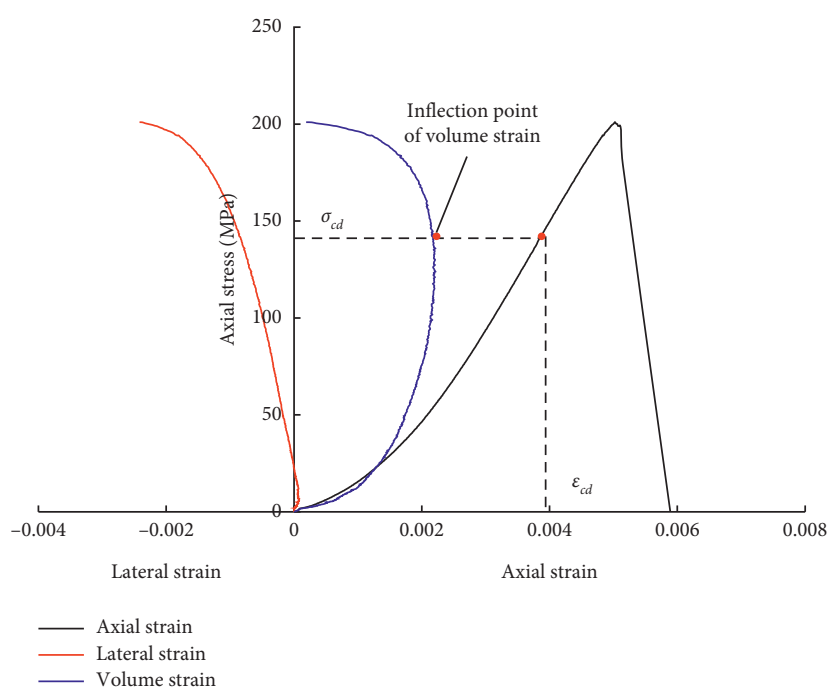

Figure 3: Sketch of the method to obtain the damage strength $\sigma_{c d}$. 


$$
B_{d}=B_{1 d} B_{2 d}=\frac{\tau_{p}-\tau_{r}}{\tau_{p}}-\left(\frac{1 \mathrm{~g}\left|k_{\mathrm{ac}(\mathrm{AC})}\right|}{10}\right) .
$$

In formula (2), $\tau_{p}$ and $\tau_{r}$ are the peak strength and residual strength, respectively. $k_{\mathrm{ac}}$ (AC) represents the postpeak stress drop rate, as shown in Figure $4 . B_{1 d}$ and $B_{2 d}$ represent the postpeak stress drop degree and drop rate, respectively. The geometric interpretation of $k_{\mathrm{ac}}(\mathrm{AC})$ means the slope of the line from the initial yielding point (i.e., point $A$ or $a$ ) to the starting point of the residual strength (i.e., point $C$ or $c$ ). For most rocks under a certain confining pressure, plastic deformation occurs, resulting in a yielding platform in the stress-strain curve and signifying a reduction in the brittleness. The peak strength and residual strength are denoted by points $B$ and $C$ on the curve [30].

Using the brittleness evaluation index $B_{d}$, the calculation results of the brittleness of three rocks are given in Table 1. According to the evaluation results of brittleness in the table, basalt has the strongest brittleness with an average value of 0.55 , followed by granite with an average value of 0.52 , and marble with an average value of 0.48 .

3.3. Evaluation of Rockburst Proneness. In order to quantitatively evaluate the rockburst proneness of rocks, up to now, rock mechanics scholars have put forward more than ten evaluation indexes or methods based on different purposes. Table 2 provides the widely used four different evaluation indexes of rockburst proneness.

Among the four rockburst proneness indexes listed in Table $2, W_{\text {et }}$ and $W_{R}$ need complex uniaxial loading and unloading tests. Because the unloading point of the unloading test is difficult to obtain accurately and the number of samples in this test is limited, the two evaluation indexes mentioned above are not used to evaluate the rockburst proneness. In addition, the calculation of $W_{c f}$ is more complicated because of the need of integral calculation based on the stress-strain curve. The index $E_{s}$ can be calculated by uniaxial compressive strength and elastic modulus. Therefore, in this section, the index $E_{s}$ was taken to analyze the rockburst proneness of three kinds of rocks. The calculation results are listed in Table 1, which show that the index $E_{s}$ of basalt, granite, and marble is $0.507,0.357$, and 0.164 , respectively. The rockburst proneness of basalt, granite, and marble belongs to the range of moderate rockburst, weak rockburst, and no rockburst, respectively.

By comparing the typical failure modes of the three kinds of rocks in Figure 5, it can be seen that obvious rock mass ejection occurs during the failure process of basalt, and residual rock blocks can be observed on the bearing head after failure of the sample. Granite shows a typical vertical splitting failure. The cracks in the sample propagate sufficiently, and the sample is split into plates and flakes by numerous vertical cracks, which is similar to the rockburst phenomenon. In the process of rock failure, if obvious shear behaviors occur, the rough fracture surface will be squeezed, and then, rock mineral particles will be rolled into powder. The marble sample is split into several rock blocks by the vertical macrofracture surface, and from the residual powder and fragments on the testing machine, it can be found that the shear mechanism plays a major role in the failure process. In addition, there is no ejection phenomenon of rock blocks and slices. It can be concluded that from the failure phenomenon and morphology of the samples, basalt has the strongest rockburst proneness, followed by granite, and marble is the weakest, which verifies the accuracy of the above evaluation results based on the rockburst proneness index.

3.4. Acoustic Emission Characteristics. In this section, the AE energy evolution characteristics and $\operatorname{AE~} b$ value of three kinds of rocks during uniaxial compression are systematically analyzed. AE hit refers to the effective rupture signal identified by the system, AE count refers to the number of shocks that exceeds the threshold value, and AE energy is a quantitative characterization parameter of the signal strength. Figure 6 shows the curves of axial stress, AE energy, and AE count with loading time. On the whole, the change trend of $\mathrm{AE}$ count and $\mathrm{AE}$ energy of rock is almost the same during uniaxial compression. It can be seen from the curve in the figure that in different deformation stages, the characteristics of $\mathrm{AE}$ energy and $\mathrm{AE}$ count of rocks are different; in the fracture compaction stage, the AE energy and AE count are always at a low level. At this stage, the closure of primary fractures and the friction of fracture surfaces will produce some acoustic emission signals, but because it is not a real rock fracture, the intensity of $\mathrm{AE}$ signal is very weak and the value of AE energy is very small. When the rock enters the linear elastic stage from the crack compaction stage, the AE count increases suddenly because of the real crack initiation and propagation in the rock (different from the compaction stage, the acoustic emission signal in the compaction stage is caused by the friction of the fracture surface of the primary crack). During the elastic and crack stable growth stage, the AE energy of basalt and marble increases steadily with the increase of loading time, while that of granite remains at a low level. After entering the stage of unstable crack propagation, the AE energy of three kinds of rocks shows different characteristics. For basalt and granite, the AE signals of high-energy continue to appear, indicating that large-scale microfracture events continue to occur; while for marble, the AE energy shows an approximate unchanged trend, and almost no high-energy signal appears. After the peak strength, basalt and granite have only a few high-energy signals. While marble is different, as the axial stress drops, the AE energy increases first and then with the continuous drop of axial stress, and the AE energy decreases sharply.

According to the abovementioned AE energy evolution characteristics and the brittleness evaluation results of the three kinds of rocks in Section 3.2, it can be concluded that brittleness has an important influence on the AE energy evolution characteristics of rocks: in the stage of unstable crack propagation, the rocks with strong brittleness continuously produce high-energy AE signals which means large-scale fractures continue to occur, while the rocks with weak brittleness hardly produce large-scale fracture. 


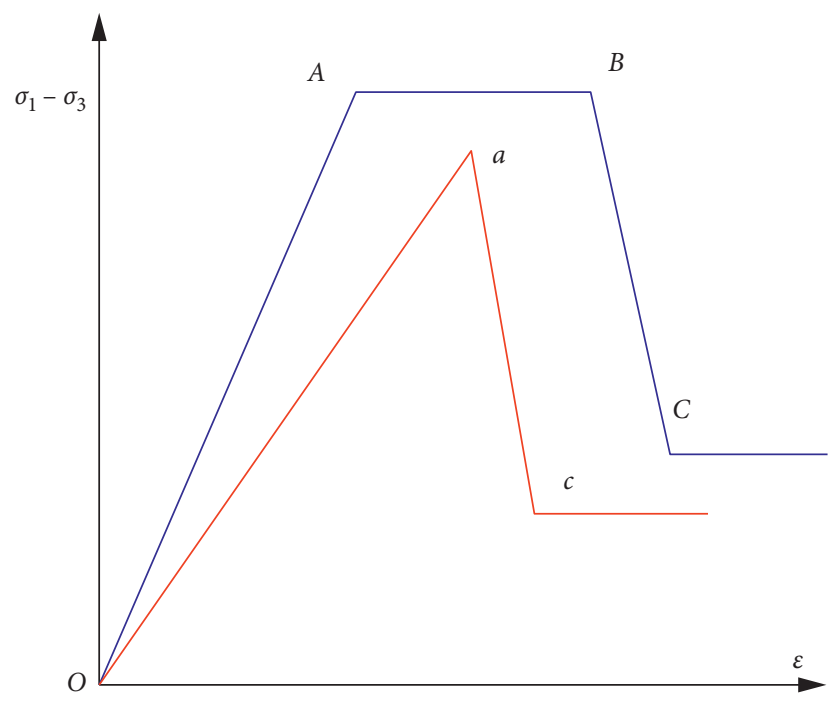

FIgURE 4: Schematic diagram of the calculation of $\mathrm{B}_{d}$.

TABLE 2: Summary of evaluation indexes for rockburst proneness.

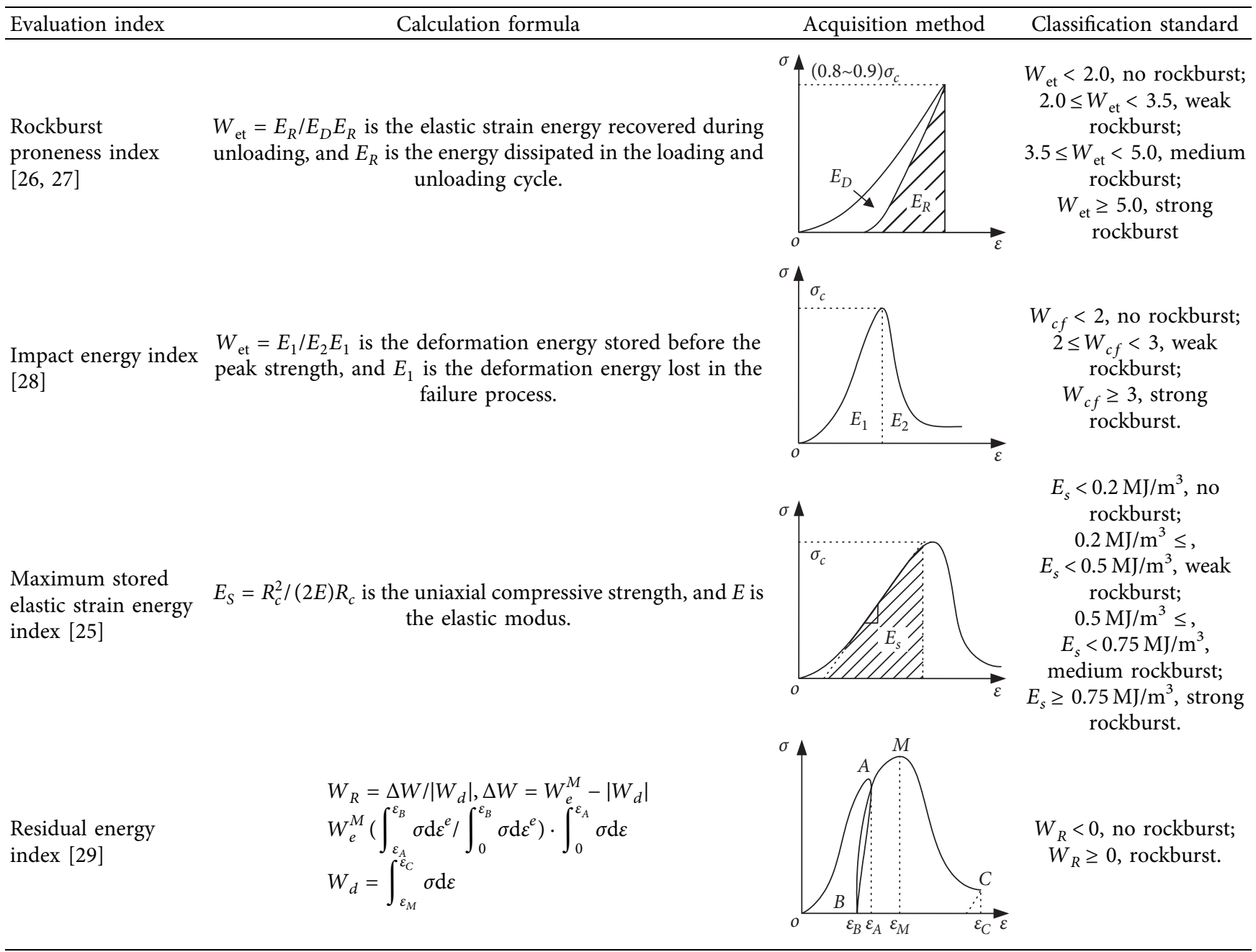




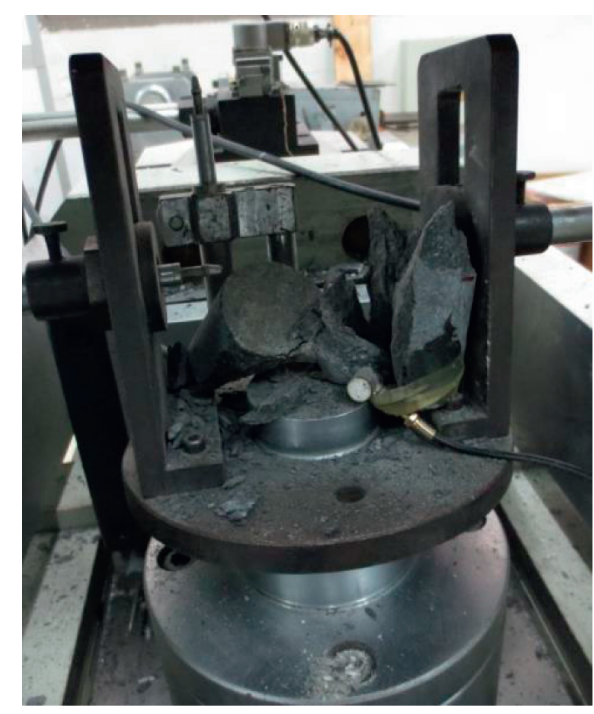

(a)

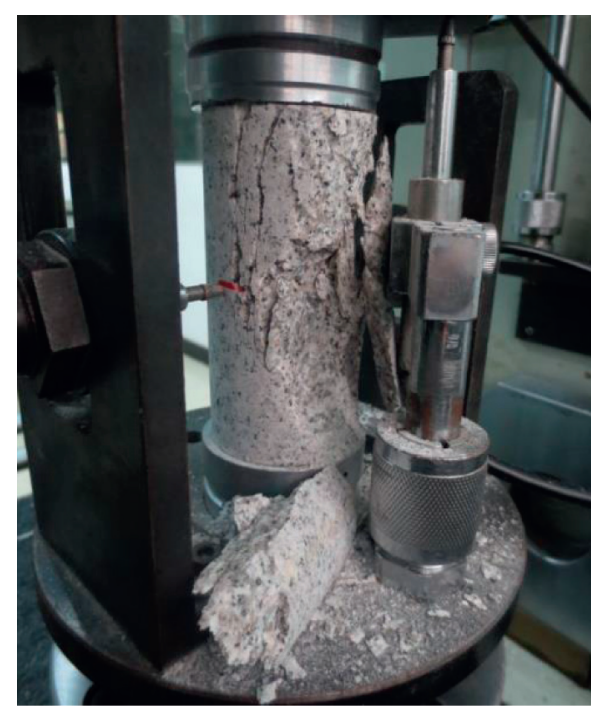

(b)



(c)

FIgURE 5: Failure modes of specimen: (a) basalt; (b) granite; (c) marble.
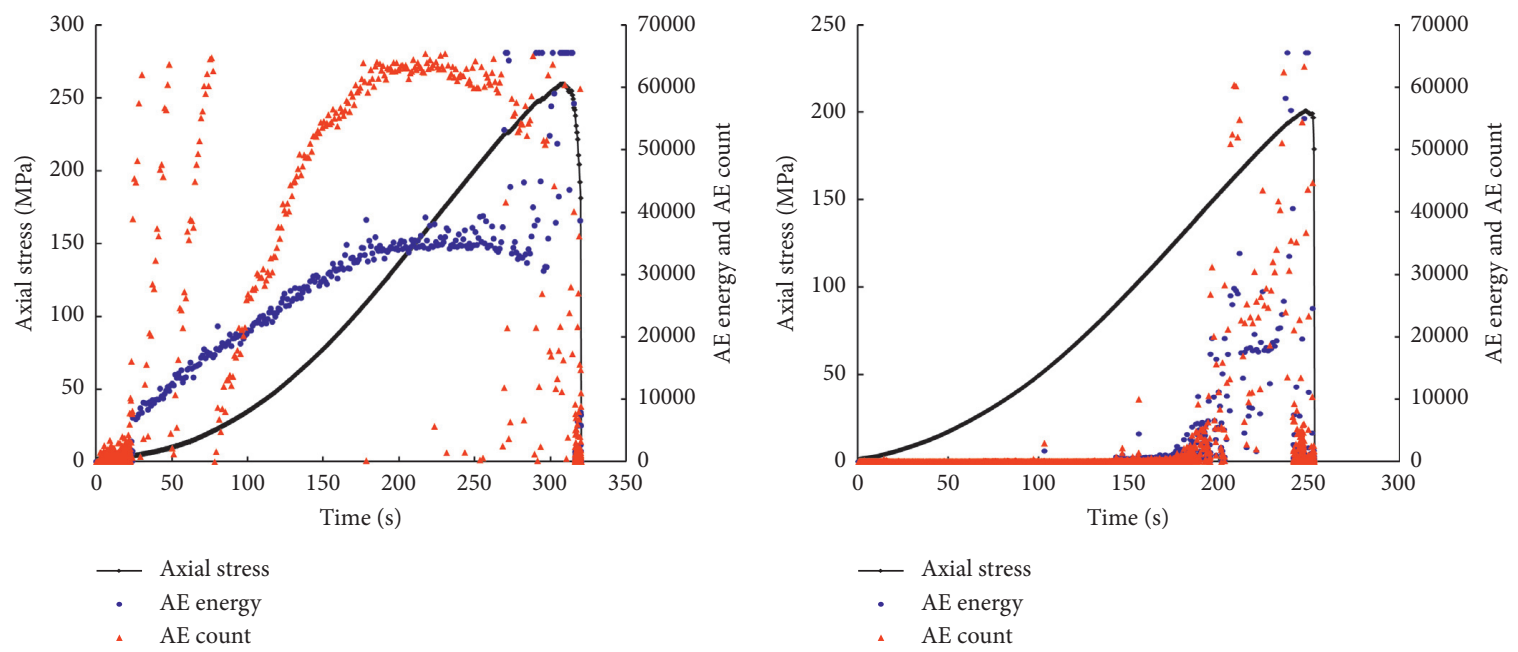

(a)

(b)

FIgURE 6: Continued. 


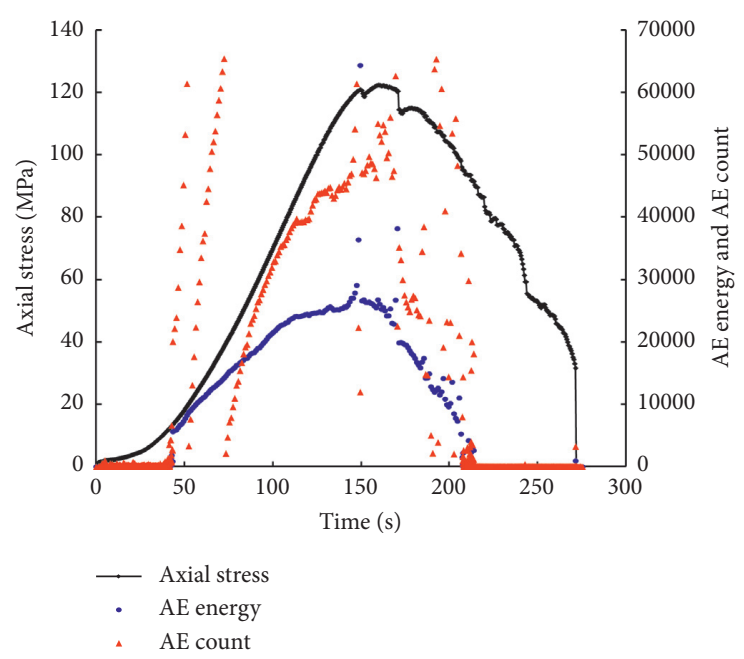

(c)

Figure 6: Change curves of axial stress, AE energy, and AE count with loading time: (a) basalt; (b) granite; (c) marble.

Figure 7 ( $\mathrm{dB}$ is the amplitude of acoustic emission, and $N$ is the number of $\mathrm{AE}$ hit) shows the distribution of $\mathrm{AE}$ amplitude in the whole process of uniaxial loading for three kinds of brittle rocks. The physical meaning of horizontal axis is the number of hits with $\mathrm{AE}$ amplitude greater than a certain value ( $>40$ means the number of hits with $\mathrm{AE}$ amplitude greater than 40). It can be seen from the figure that the number of AE hit with high amplitude (greater than $75 \mathrm{~dB}$ ) of marble is much less than that of basalt and granite in the whole process of rock failure. It can be seen that for marble with weak brittleness, although there are many fractures generated in the rock during the deformation and failure process, most of them belong to small-scale microfractures.

The AE $b$ value comes from the study of seismology. The $\mathrm{AE} b$ value can reflect the proportional relationship between large-scale fracture and small-scale fracture in the process of rock fracture. The smaller the $\mathrm{AE} b$ value, the greater the ratio of macrocracks to microcracks during the failure process. The algorithm for specific acoustic emission $b$ value is calculated according to the following formula $[8,31,32]$ :

$$
\log N=a-b \frac{A_{\mathrm{dB}}}{20} .
$$

As shown in Figure 8, according to the linear fitting results, the $\mathrm{AE} b$ value of basalt is 0.53 , that of granite is 1.02 , and that of marble is 1.29 . Combined with the physical meaning of $\mathrm{AE} b$ value, it can be concluded that the stronger the brittleness of rock, the larger the proportion of largescale fracture events in the failure process.

\section{Discussion}

Rockburst is a kind of dynamic disaster in which the strain energy in the surrounding rock is released suddenly in a very short period of time, and the rock mass ejection is a typical external manifestation [33, 34]. Strong brittleness and good ability of storage of strain energy are the necessary

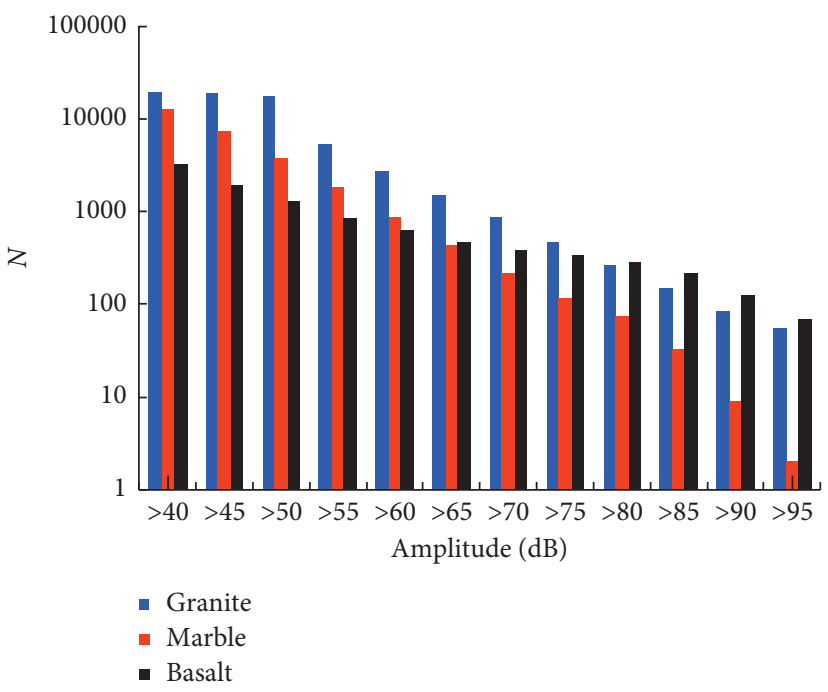

Figure 7: Distribution of AE amplitude.

conditions for rock mass to form rockburst disaster after excavation. Brittleness means the sudden failure of surrounding rock, which creates conditions for the sudden release of elastic energy accumulated in surrounding rock. The rockburst proneness index emphasizes the possibility of rockburst from the aspect of energy storage. If there exists a certain fitting relationship between the brittleness index of rock and its burst proneness index, the rockburst proneness index (or the brittleness index) can be calculated according to the rock brittleness index (or the rockburst proneness index), and in this way, the number of tests to be carried out will be greatly reduced.

According to the calculation results of brittleness and rockburst proneness in Section 3, there is a positive correlation between brittleness and rockburst proneness, that is, the stronger the brittleness, the larger the rockburst proneness. Figure 9 shows the relationship between the two indexes $B_{d}$ and $E_{s}$. The black line represents the result of 


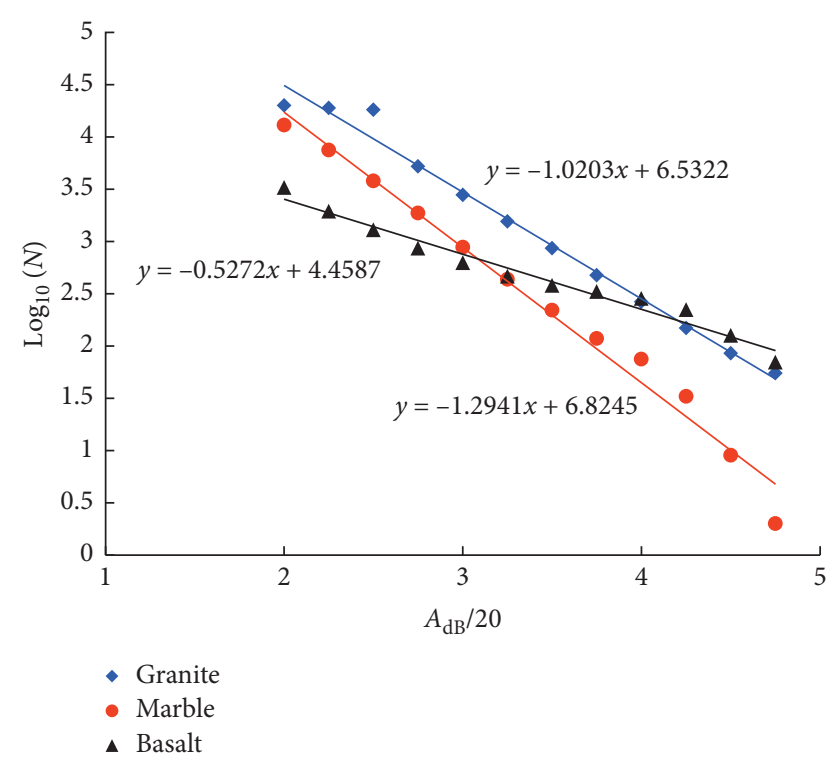

Figure 8: Fitting curves of AE $b$ value.



Figure 9: Relationship between $B_{d}$ and $E_{s}$.

linear fitting, while the blue curve represents the result of exponential fitting. According to the fitting curve, there is an exponential relationship between rockburst proneness and rock brittleness. It should be pointed out that the accuracy of the fitting formula is not high due to the small amount of data obtained in this test, and more tests are needed to verify the accuracy of the conclusion. In addition, since we have not carried out other relevant tests to measure other rockburst proneness indexes, the relationship between rock brittleness index $B_{d}$ and other rockburst proneness indexes is not obtained.

\section{Conclusions}

In this study, the uniaxial compression test is carried out for basalt, granite, and marble, and the brittleness and rockburst proneness of the three kinds of rock are quantitatively evaluated. Through analysis of the acoustic emission evolution characteristics, the differences of the fracture mechanism of the three kinds of rocks are compared. The main conclusions are as follows:

(1) Based on the quantitative evaluation index of brittleness $B_{d}$, the brittleness of the three rocks is compared. The results show that basalt is the most brittle, followed by granite, and marble is the weakest.

(2) Based on the evaluation index of rockburst proneness $E_{s}$, combined with the macroscopic failure phenomenon and morphology of samples, basalt has the strongest rockburst proneness, followed by granite and marble. There is a positive correlation between brittleness and rockburst proneness, that is, the stronger the brittleness, the larger the rockburst proneness. The fitting results show that there is an exponential relationship between brittleness index $B_{d}$ and rockburst proneness $E_{s}$.

(3) Different from marble, both the basalt and granite with strong brittleness continuously present highenergy acoustic emission signals in the stage of unstable crack propagation, which means large-scale fractures continue to occur.

(4) According to the calculation results of the $\mathrm{AE} b$ value and its physical significance, for basalt and granite with stronger brittleness, the proportion of largescale fracture events in the failure process is larger than that of marble.

\section{Data Availability}

The data used to support the findings of this study are available from the corresponding author upon request.

\section{Conflicts of Interest}

The authors declare that they have no conflicts of interest.

\section{Acknowledgments}

The authors would like to acknowledge the financial support by the National Natural Science Foundation of China (51709113).

\section{References}

[1] F. Meng, L. Ngai Yuen Wong, and H. Zhou, "Review of rock brittleness indices and their applications in different fields of rock engineering," Journal of Rock Mechanics and Geotechnical Engineering, vol. 13, no. 1, pp. 221-247, 2020.

[2] Z. Li, H. Zhou, Y. Jiang, D. Hu, and C. Zhang, "Methodology for establishing comprehensive stress paths in rocks during hollow cylinder testing," Rock Mechanics and Rock Engineering, vol. 52, no. 4, pp. 1055-1074, 2019.

[3] W. Y. Guo, F. H. Yu, Y. L. Tan, and T. B. Zhao, "Experimental study on the failure mechanism of layer-crack structure," Energy Science \& Engineering, vol. 7, no. 6, pp. 2351-2372, 2019. 
[4] J. Yu, W. Yao, K. Duan, X. Liu, and Y. Zhu, "Experimental study and discrete element method modeling of compression and permeability behaviors of weakly anisotropic sandstones," International Journal of Rock Mechanics and Mining Sciences, vol. 134, Article ID 104437, 2020.

[5] S. Hu, Y. Tan, H. Zhou et al., "Anisotropic modeling of layered rocks incorporating planes of weakness and volumetric stress," Energy Science \& Engineering, vol. 8, no. 3, pp. 789-803, 2020.

[6] J. Yu, G. Liu, Y. Cai, J. Zhou, S. Liu, and B. Tu, "Time-dependent deformation mechanism for swelling soft-rock tunnels in coal mines and its mathematical deduction," International Journal of Geomechanics, vol. 20, no. 3, Article ID 04019186, 2020.

[7] A. Morley, Strength of Materials, Longman Green, London, UK, 1944.

[8] H. R. Nejati and A. Ghazvinian, "Brittleness effect on rock fatigue damage evolution," Rock Mechanics and Rock Engineering, vol. 47, no. 5, pp. 1839-1848, 2014.

[9] V. A. Akinbinu, "Relationship of brittleness and fragmentation in brittle compression," Engineering Geology, vol. 221, pp. 82-90, 2017.

[10] R. Altindag, "Assessment of some brittleness indexes in rockdrilling efficiency," Rock Mechanics and Rock Engineering, vol. 43, no. 3, pp. 361-370, 2010.

[11] Q. H. Li, M. Chen, Y. Jin, F. P. Wang, and B. Hou, "Indoor evaluation method for shale brittleness and improvement," Chinese Journal of Rock Mechanics and Engineering, vol. 31, no. 8, pp. 1680-1686, 2012.

[12] A. Tarokh, J. Peng, A. Fakhimi, and J. F. Labuz, "Evaluation of brittleness from spalling and bending test," in Proceedings of the 50th US Rock Mechanics/Geomechanics Symposium, American Rock Mechanics Association, Houston, TX, USA, June 2016

[13] C. Ai, J. Zhang, Y.-W. Li, J. Zeng, X.-L. Yang, and J.-G. Wang, "Estimation criteria for rock brittleness based on energy analysis during the rupturing process," Rock Mechanics and Rock Engineering, vol. 49, no. 12, pp. 4681-4698, 2016.

[14] Y. J. Xia, L. C. Li, C. A. Tang, X. Y. Li, S. Ma, and M. Li, “A new method to evaluate rock mass brittleness based on stressstrain curves of class I," Rock Mechanics and Rock Engineering, vol. 50, no. 5, pp. 1123-1139, 2017.

[15] G. Chen, C. Zhao, T. Wei, and J. Wang, "Evaluation method of brittle characteristics of rock based on full stress-strain curve and crack initiation stress," Chinese Journal of Rock Mechanics and Engineering, vol. 37, no. 1, pp. 51-59, 2018.

[16] E. Eberhardt, D. Stead, B. Stimpson, and R. S. Read, "Identifying crack initiation and propagation thresholds in brittle rock," Canadian Geotechnical Journal, vol. 35, no. 2, pp. 222-233, 1998.

[17] E. Eberhardt, D. Stead, and B. Stimpson, "Quantifying progressive pre-peak brittle fracture damage in rock during uniaxial compression," International Journal of Rock Mechanics and Mining Sciences, vol. 36, no. 3, pp. 361-380, 1999.

[18] F. Meng, L. Ngai Yuen Wong, H. Zhou, Z. Wang, and L. Zhang, "Quantifying progressive pre-peak brittle fracture damage in rock during uniaxial compression," Engineering Geology, vol. 266, no. 5, pp. 1-14, 2020.

[19] H. Zhou, F. Meng, J. Lu, C. Zhang, and F.-J. Yang, "Discussion on methods for calculating crack initiation strength and crack damage strength for hard rock," Rock and Soil Mechanics, vol. 35, no. 4, pp. 913-925, 2014.

[20] H. W. Zhou, Z. H. Wang, W. G. Ren, Z. L. Liu, and J. F. Liu, "Acoustic emission based mechanical behaviors of Beishan granite under conventional triaxial compression and hydromechanical coupling tests," International Journal of Rock Mechanics and Mining Sciences, vol. 123, Article ID 104125, 2019.

[21] L. N. Y. Wong and T. Y. Guo, "Microcracking behavior of two semi-circular bend specimens in mode I fracture toughness test of granite," Engineering Fracture Mechanics, vol. 221, Article ID 106565, 2019.

[22] C. Q. Zhang, J. J. Lu, J. Chen, H. Zhou, and F.- J. Yang, "Discussion on rock burst proneness indexes and their relation," Rock and Soil Mechanics, vol. 38, no. 5, pp. 1397-1404, 2017.

[23] N. Y. W. Louis, F. Meng, T. Guo, and X. Shi, "The role of load control modes in determination of mechanical properties of granite," Rock Mechanics and Rock Engineering, vol. 53, pp. 539-552, 2020.

[24] R. C. Xu and H. Zhou, "Experimental investigation of the anchoring effect of two different types of rock bolts on fractured rock," Advances in Materials Science and Engineering, vol. 2019, Article ID 9290318, 10 pages, 2019.

[25] J.-A. Wang and H. D. Park, "Comprehensive prediction of rockburst based on analysis of strain energy in rocks," Tunnelling and Underground Space Technology, vol. 16, no. 1, pp. 49-57, 2001.

[26] A. Kidybinski, "Bursting liability indices of coal," International Journal of Rock Mechanics and Mining Science \& Geomechanics Abstracts, vol. 18, pp. 295-304, 1981.

[27] S. P. Singh, "Technical note: burst energy release index," Rock Mechanics and Rock Engineering, vol. 21, no. 2, pp. 149-155, 1988.

[28] R. Guo and R. C. Yu, "Working procedure of developing a new deep hard-rock burst-prone deposit," Engineering Sciences, vol. 4, no. 7, pp. 51-55, 2002.

[29] L. Z. Tang, C. L. Pan, and W. X. Wang, "Surplus energy index for analyzing rock burst proneness," Journal of Central South University of Technology, vol. 33, no. 2, pp. 129-132, 2002.

[30] F. Meng, H. Zhou, C. Zhang, R. Xu, and J. Lu, "Evaluation methodology of brittleness of rock based on post-peak stressstrain curves," Rock Mechanics and Rock Engineering, vol. 48, no. 5, pp. 1787-1805, 2015.

[31] J. H. Kurz, F. Finck, C. U. Grosse, and H.-W. Reinhardt, "Stress drop and stress redistribution in concrete quantified over time by the b-value analysis," Structural Health Monitoring, vol. 5, no. 1, pp. 69-81, 2006.

[32] F. Meng, L. N. Y. Wong, H. Zhou, J. Yu, and G. Cheng, "Shear rate effects on the post-peak shear behaviour and acoustic emission characteristics of artificially split granite joints," Rock Mechanics and Rock Engineering, vol. 52, no. 7, pp. 2155-2174, 2019.

[33] H. Zhou, F. Meng, C. Zhang, D. Hu, F. Yang, and J. Lu, "Analysis of rockburst mechanisms induced by structural planes in deep tunnels," Bulletin of Engineering Geology and the Environment, vol. 74, no. 4, pp. 1435-1451, 2014.

[34] W. D. Ortlepp and T. R. Stacey, "Rockburst mechanisms in tunnels and shafts," Tunnelling and Underground Space Technology, vol. 9, no. 1, pp. 59-65, 1994. 